\title{
A cornerstone of healthy aging: do we need to rethink the concept of adherence in the elderly?
}

This article was published in the following Dove Press journal:

Patient Preference and Adherence

\author{
Anna Giardini' \\ Marina Maffoni ${ }^{2}$ \\ Przemyslaw Kardas ${ }^{3}$ \\ Elisio Costa ${ }^{4}$ \\ 'Psychology Unit, Istituti Clinici \\ Scientifici Maugeri Spa SB, IRCSS \\ Montescano, Montescano (PV), Italy; \\ ${ }^{2}$ Department of Brain and Behavioural \\ Sciences, University of Pavia, Pavia, \\ Italy; ${ }^{3}$ Department of Family Medicine, \\ Medical University of Lodz, Lodz, \\ Poland; ${ }^{4}$ Elísio Costa, UCIBIO- \\ REQUIMTE, Faculty of Pharmacy and \\ Porto4Ageing EIP-AHA Reference \\ Site, University of Porto, Porto, \\ Portugal
}

\begin{abstract}
Worldwide, the population is aging and this trend will increase in the future due to medical, technological and scientific advancements. To take care of the elderly is highly demanding and challenging for the health care system due to their frequent condition of chronicity, multimorbidity and the consequent complex management of polypharmacy. Nonadherence to medications and to medical plans is a well-recognized public health problem and a very urgent issue in this population. For this reason, some considerations to identify a new shared approach to integrated care of older people are described. The concept of adherence should be considered as a complex and continuous process where family, caregivers and patients' beliefs come into play. Moreover, a new culture of adherence should contemplate the complexity of multimorbidity, as well as the necessity to renegotiate the medication regimen on the basis of each patient's needs.
\end{abstract}

Keywords: population aging, chronicity, multimorbidity, polypharmacy, nonadherence

\section{Introduction}

The world is facing an aging phenomenon due to individuals living longer than ever before. In 2015, 901 million people were aged $\geq 60$ years, with most of these individuals living in developed countries. This number is expected to more than double by 2050 , reaching 2.1 billion (ie, $20 \%$ of the global population). Moreover, the number of people aged $>80$ years is growing more rapidly than the general elderly population. Approximately $14 \%$ of the elderly population ( 125 million) were $\geq 80$ years in 2015 , and this number is expected to triple by 2050, reaching 434 million (approximately 20\% of the senior population). ${ }^{1}$ This phenomenon puts clear pressure on health care systems and social service support structures. Older adults typically exhibit the co-occurrence of multiple conditions and chronic diseases, which makes their care, particularly their use of medications, a challenging task. Indeed, more than $90 \%$ of older adults are prescribed drugs, $50 \%$ of whom take five or more drugs and $10 \%$ of whom take 10 or more. ${ }^{2}$ Prevalence of polypharmacy (defined as at least five prescribed medications) in the elderly increases with age. It is reported that $36 \%-49 \%$ of patients $>75$ years are prescribed polymedication, with differences related to the cohort considered and to nationality. ${ }^{3-6}$ Nonadherence to medication and to medical plans, in general, are well-recognized public health problems. It is a challenge for researchers and health care providers as numerous efforts to improve patient adherence and persistence appear to be ineffective. ${ }^{7}$ This is particularly important in older adults due to the high number of coexisting chronic diseases and geriatric syndromes.

We must, therefore, deal with new challenges in a more holistic health care supervision and support of the elderly, both in health care systems and in home-settings,
Correspondence: Anna Giardini Servizio di Psicologia, Istituto Scientifico di Montescano (PV), ICS Maugeri, 27040 Montescano (PV), Italy Email anna.giardini@icsmaugeri.it 
to enable the management of highly complex issues that require the integration of competencies of different social and health care professionals. Older people's adherence to medical plans constitutes an essential part of this trip toward adding quality to life rather than adding years to life.

When considering the definition of adherence, it must be considered that many different languages are spoken, leading to misunderstandings and incomprehension. Many different terms have been interchangeably used to describe adherence, which leaves a significant level of confusion. Adherence to medication is the term that is most commonly used, thanks to the World Health Organization definition of adherence ${ }^{8}$ and the ABC taxonomy. ${ }^{9}$ Nevertheless, even though it constitutes a clinical and scientific cornerstone, it may not adequately describe the need for a holistic adherence approach when dealing with the older population. Do we therefore need to rethink the culture of adherence in the elderly? Perhaps we need to integrate some unusual aspects that mainly characterize the older generation and that have been unforeseen or underestimated to date.

\section{Toward a dedicated perspective on adherence in the elderly}

It is uncommon for an older person to follow their therapeutic regimen on their own; for example, a formal or informal caregiver usually plays an essential role in adherence, ${ }^{10}$ as well as occurring in pediatric care. ${ }^{11}$ At the same time, clinical experience suggests that caregivers may often become a patient themselves. Therefore, should we speak of a patient's adherence or a family's adherence? Moreover, whenever a paid caregiver is involved in the care process, we should also consider the environmental context (ie, caregiver's adherence). Interventions aimed at improving adherence in the elderly population should therefore not only be individually oriented but also be family and caregiver oriented. ${ }^{12,13}$ Hence, a new definition of the concept of adherence needs to consider its changing nature, accepting that adherence is a process and not a status. It should be well illustrated with expectations from the medication review, and together with patients and their caregivers, renegotiate the medication regimen. ${ }^{14,15}$

Moreover, increased adherence not only positively impacts on patients' health but also allows cost savings in the health care system to be achieved and productivity improvements in the economy. To increase adherence in the elderly may reduce payout due to slower disease progression and lower recurrence of relapse episodes. On the other hand, it may increase payout due to increased medication use and short-term services too. However, the balance is positive for insurances. ${ }^{16}$

With regards to multimorbidity, the same individual may express different levels of adherence to different medications due to prioritization and individual health-belief models. ${ }^{14}$ Nevertheless, clinical trials seldom include the elderly and rarely focus on polypharmacy. The conceptual change should therefore accept a move toward a systemic view and away from a disease-specific position. Moreover, adherence is not always the result of an international and active behavioral process influenced by beliefs, feelings and environmental factors. On the contrary, in this kind of population the non-intentional adherence is an issue. Indeed, the elderly often deal with physiological decline of their sensorial, functional and cognitive capacities, as well as with neurodegenerative diseases. Poverty of cognitive resources contributes to the difficulty in fully understanding and managing medical prescriptions. The difficulties grow exponentially as the coexisting pathologies and treatments increase. ${ }^{17}$ Indeed, it has been reported that adherence may be different in clinical populations throughout the aging and in the change in neuropsychological functioning. ${ }^{18}$

\section{Conclusions}

Therefore, what is the landscape of adherence in elderly nowadays? Do we need to implement a "one fits all model" or should our clinical approach fit each individual and thus meet the expectations of personalized medicine while maintaining a sound cost-effectiveness ratio? What about the questions regarding adherence in an elderly population? The need of a more individualized and socially supportive medical regimen has already been proposed. ${ }^{19,20}$ Besides that, we highlight the need of a more holistic approach to adherence to create a new and shared culture of adherence in the elderly. Clinicians, health and social care professionals, researchers and stakeholders need to talk the same language to advocate policy frameworks that put adherence, particularly in chronic patients, on national and regional agendas. Deserved attention should be given to education, the implementation of interventional tools and clinical needs.

\section{Disclosure}

A Giardini, P Kardas and E Costa are coordinators (AG and EC) or promoters (PK) of Action Group A1 "Prescription and adherence to treatment" of the European Innovation Partnership on Active and Healthy Ageing, and partners of the Erasmus plus project Skills4Adherence (2017-1-PL01KA202-038672). The authors report no other conflicts of interest in this work. 


\section{References}

1. World Health Organization. World population ageing 2015. Available from: http://www.un.org/en/development/desa/population/publications/ pdf/ageing/WPA2015_Report.pdf. Accessed December 15, 2017.

2. Onder G, Bonassi S, Abbatecola AM, et al. High prevalence of poor quality drug prescribing in older individuals: a nationwide report from the Italian Medicines Agency (AIFA). J Gerontol A Biol Sci Med Sci. 2014;69(4):430-437.

3. Hernández Perella JA, Mas Garriga X, Riera Cervera D, Quintanilla Castillo R, Gardini Campomanes K, Torrabadella Fàbregas J. [Inappropriate prescribing of drugs in older people attending primary care health centres: detection using STOPP-START criteria]. Rev Esp Geriatr Gerontol. 2013;48(6):265-268. Spanish.

4. Maher RL Jr, Hanlon J, Hajjar ER. Clinical consequences of polypharmacy in elderly. Expert Opin Drug Saf. 2014;13(1):57-65.

5. Stewart D, Mair A, Wilson M, et al. Guidance to manage inappropriate polypharmacy in older people: systematic review and future developments. Expert Opin Drug Saf. 2017;16(2):203-213.

6. Pérez-Jover V, Mira JJ, Carratala-Munuera C, et al. Inappropriate use of medication by elderly, polymedicated, or multipathological patients with chronic diseases. Int J Environ Res Public Health. 2018;15(2):pii:E310.

7. Costa E, Giardini A, Savin M, et al. Interventional tools to improve medication adherence: review of literature. Patient Prefer Adherence. 2015;9:1303-1314.

8. World Health Organization [webpage on the Internet]. Adherence to long-term therapies: evidence for action. 2003. Available from: http:// apps.who.int/medicinedocs/en/d/Js4883e/. Accessed December 20, 2017.

9. Vrijens B, De Geest S, Hughes DA, et al. A new taxonomy for describing and defining adherence to medications. Br J Clin Pharmacol. 2012; 73(5):691-705.

10. Gillespie R, Mullan J, Harrison L. Managing medications: the role of informal caregivers of older adults and people living with dementia. A review of the literature. J Clin Nurs. 2014;23(23-24):3296-3308.
11. Rapoff MA. Adherence to Pediatric Medical Regimens. 2nd ed. USA: Springer; 2010.

12. Toukhsati SR, Hare DL. Towards optimal heart failure care: couplesoriented strategies to improve patient adherence and health outcomes. Curr Cardiol Rev. 2016;12(3):243-248.

13. Bryant J, Mansfield E, Boyes AW, Waller A, Sanson-Fisher R, Regan T. Involvement of informal caregivers in supporting patients with COPD: a review of intervention studies. Int J Chron Obstruct Pulmon Dis. 2016;11:1587-1596.

14. Prados-Torres A, Del Cura-González I, Prados-Torres D, et al. Effectiveness of an intervention for improving drug prescription in primary care patients with multimorbidity and polypharmacy: study protocol of a cluster randomized clinical trial (multi-PAP project). Implement Sci. 2017;12(1):54

15. Onder G, Marengoni A. Polypharmacy. JAMA. 2017;318(17):1728.

16. Behner P, Klink A, Visser S, Böcken J, Etgeton S. Unleashing the Potential of Therapy Adherence High-Leverage Changes in Patient Behavior for Improved Health and Productivity; 2012. Available from: https://www.strategyand.pwc.com/media/uploads/Strategyand_ BS_Unleashing-the-Potential-of-Therapy-Adherence.pdf. Accessed March 22, 2018.

17. Smith D, Lovell J, Weller C, et al. A systematic review of medication non-adherence in persons with dementia or cognitive impairment. PLoS One. 2017;12(2): 0170651.

18. Corréard N, Consoloni JL, Raust A, et al. Neuropsychological functioning, age, and medication adherence in bipolar disorder. PLoS One. 2017;12(9):e0184313.

19. Bergman-Evans B. AIDES to improving medication adherence in older adults. Geriatr Nurs. 2006;27(3):174-182.

20. American Society on Aging (ASA) [webpage on the Internet]. American Society of Consultant Pharmacists (ASCP Foundation). Adult Meducation. ${ }^{\mathrm{TM}}$ Improving Medication Adherence in Older Adults. Available from: http://learning.rxassist.org/adult-meducation-improvingmedication-adherence-older-adults-asa-ascpf. Accessed March 19, 2018
Patient Preference and Adherence

\section{Publish your work in this journal}

Patient Preference and Adherence is an international, peer-reviewed, open access journal that focuses on the growing importance of patient preference and adherence throughout the therapeutic continuum. Patient satisfaction, acceptability, quality of life, compliance, persistence and their role in developing new therapeutic modalities and compounds to optimize

\section{Dovepress}

clinical outcomes for existing disease states are major areas of interest for the journal. This journal has been accepted for indexing on PubMed Central. The manuscript management system is completely online and includes a very quick and fair peer-review system, which is all easy to use. Visit http://www. dovepress.com/testimonials.php to read real quotes from published authors. 